\title{
Social Perceptions of People Living with HIV/AIDS using Multivariate Analysis for Public Health Planning
}

\author{
Jayarajan.K* \\ Assistant Professor of Geography, Department of Geography, Govt .College Chittur, Palakkad, Kerala \\ "Corresponding Author: Jayarajan.K, Assistant Professor of Geography, Department of Geography, \\ Govt .College Chittur, Palakkad, Kerala, India
}

\begin{abstract}
HIV/AIDS-related stigma is "a term that refers to prejudice, discounting, discrediting, and inequity directed at people perceived to have AIDS or HIV, and the individuals, groups, and communities with which they are associated" Such stigmas have been recognized in varying forms throughout the world, ranging from personal attacks to loss of jobs or homes to discriminatory legislation. These stigmas even impact the behaviour of people who have HIV/AIDS themselves and those associated with them. When a virulent pandemic like HIVIAIDS emerges in a society or globally, drastic social action is needed to reduce the impact. Unlike other viruses or diseases, there is no vaccination or cure for HIV/AIDS, so a "simple" clarification of inoculations could not be administered on such a massive scale. When these limitations are recognized, the task of reducing the spread and impact of a pandemic like HIV/AIDS becomes much more challenging. The colossal task then becomes getting millions of people to change their everyday behaviour. This is not easy to do. The present study aims to analyze the spatial distribution of people living with HIV/AIDS and their relationship between social, cultural, psychological and health condition. The multivariate statistical technique of factor analysis is applied to study the multi dimentional inter related variables included in the research study. Based on analysis the Eigen value 6.49 is considered as a yardstick to extract 10 factors and the same are resolved owing to the fact that almost all the variables got loaded with these factors. The 10 factors explain altogether $89.58 \%$ of the total variance with each one of its value ranging from $6.49 \%$ to $12.31 \%$. Though the components selected as 10 factors, it is pertinent to note the fact the first 5 primary factors that have more than 8.93 Eigen values alone totally explain $53.84 \%$ of total variance whereas the remaining 5 factors recorded with more than (6.49-7.61). The social, cultural, psychological and health condition are considered for the present analysis and identified the problematic region in the block level i.e. Pattambi, Sreekrishnapuram and Attapadi block represented very high HIV/AIDS related problems whereas very low HIV/AIDS related problems are represented in the blocks of Chittur, Nenmara-, Thrithala, and Ottapalam- this will be ready to lend a hand for a sustainable planning to the future.
\end{abstract}

Keywords: Eigen Value, Multivariate Analysis, PLHA, Stigma, Spatial Distribution

\section{INTRODUCTION}

Kerala has often been singled out as a paradox in having achieved 'good health at low cost'. The State is reported to have the lowest rural-urban inequalities in public health status. HIV/AIDS-related stigma is "a term that refers to prejudice, discounting, discrediting, and inequity directed at people perceived to have AIDS or HIV, and the individuals, groups, and communities with which they are associated" Such stigmas have been recognized in varying forms throughout the world, ranging from personal attacks to loss of jobs or homes to discriminatory legislation. Geographic variation in population, and population need for health care, provides the foundation for analysis and planning of health services. People are not spread evenly across the earth's surface, and populations differ along many dimensions including age, gender, culture, and economic status that affect their need for health care, their ability to travel to obtain health care, and the types of services they are willing and able to utilize.

Health is vital for all of us and understanding the determinants of a disease, its spread from person to person and community to community has become increasingly global. There are various factors such as climate, environment, water quality and management, pollution, natural disasters, education, social and many others which are the reasons for the emergence of diseases. The characteristics of these 
locations (including socio-demographic and environmental exposure) offer a valuable source for epidemiological research studies on health and the environment. Since health is a geographical phenomenon and various factors attributing to the health diagnostics and planning are geography dependent, as such GIS (Geographic Information System) for health studies serves as an important tool. Some of its applications in public health are: (1) geographical distribution and variation of diseases (2) analysis of spatial and temporal trends (3) identifying gaps in immunizations (4) mapping populations at risk and stratifying risk factors (5) documenting health care needs of a community and assessing resource allocations (6) forecasting epidemics (7) planning and targeting interventions (8) monitoring diseases and interventions over time (9) managing patient care environments, materials, supplies and human resources (10) monitoring the utilization of health centers (11) route health workers, equipments and supplies to service locations (12) publishing health information using maps, etc. Geographic Information System is not the complete solution to understanding the distribution of disease and the problems of public health but is an important way in which to better illuminate how humans interact with their environment to create or deter health. Geographic Information System provides excellent means for visualizing and analyzing epidemiological data, revealing trends, dependencies and inter-relationships. It can acquire, store, manage, and geographically integrate large amounts of information from different sources, programmes and sectors.

\subsection{Location of the Study Area}

Palakkad district is Situated at the foot of western ghats, this is the gateway of Kerala from north. Palakkad district is placed between $10^{\circ} 20^{\prime} \mathrm{N}$ to $11^{\circ} 14^{\prime} \mathrm{N}$ latitude and $76^{\circ} 20^{\prime} \mathrm{E}$ to $76^{\circ} 54^{\prime} \mathrm{E}$ longitude figure 1.1. The district shares borders with Malappuram district in the North and Northwest, Thrissur in the South and Southwest and Coimbatore district of Tamil Nadu in the East. Out of the 14 districts of Kerala, Palakkad is one of the five districts which does not have a coastline. Its geographical position, historical background, rural nature, educational status, tourist attractions and above all, the developmental activities are wide and varied. There are thirteen Development blocks and four Municipalities in the district. Ninety one Panchayats are grouped to form the thirteen blocks.

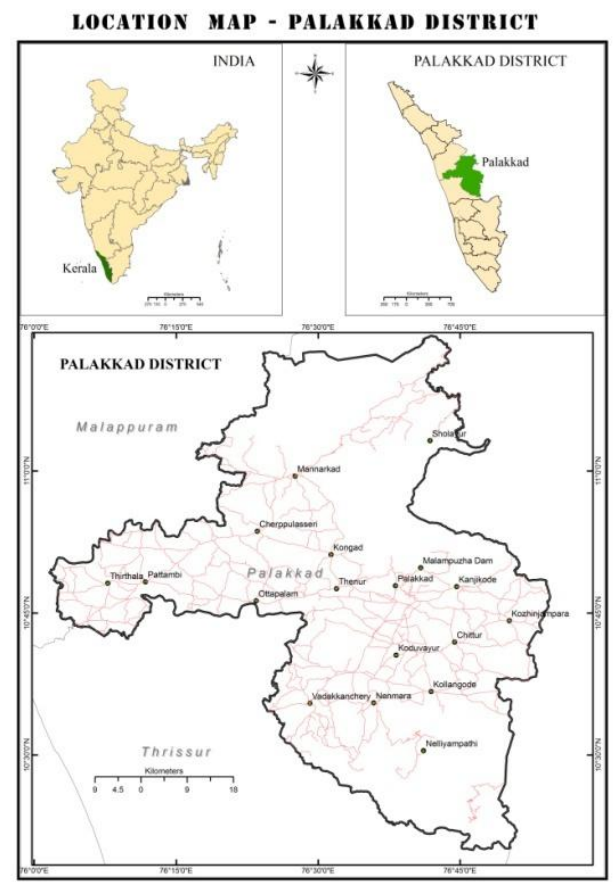

Figure 1.1

\subsection{Aim and Objectives}

- To make integrate the data with statistical analysis in order to identify major problems of the People living with HIV/AIDS and the Spatial disparity in the distribution to control the spread of HIV /AIDS and suggest suitable planning multivariate GIS based Planning strategy for improving the status of People Living with HIV/AIDS in Palakkad district in Kerala State. 


\section{METHODS}

The present study based on both Primary and Secondary data. Secondary data is collected from Governmental and quasi Govt agencies. The secondary data includes the enrolment of the People Living with HIV/AIDS (casualty sheets) registers of Pratiasa Centers, registers of NGOs i.e. Council of People Living With HIV/AIDS (CPK+) Published information collected from the Govt organization like National AIDS Control Organization (NACO), Kerala State AIDS Control Organization (KASACS) and various NGO, ie National AIDS Control Organization (NACO) surveillance report and Kerala State Surveillance report, UNAIDS surveillance report also collected. Council of People Living with HIV/AIDS (CPK+) enrolment is collected from 2004 onwards.

Random sampling method is applied for primary data collection from the Pratyasa centers and Council of people living with HIV/AIDS in Palakkad district. In this intention total reported cases up to 2010-11 year are considered for the present study .In this random sampling 20 percent of the reported cases in Pratyasa Centres in Palakkad districts are well thought-out. Here 180 samples are collected for the investigation by using elaborate questionnaire. To collect the information required for the study a structured interview schedule was prepared. Before structuring the interview schedule discussions were held with a few People living with HIV/AIDS. In the preparation of the interview schedule, Health survey schedules used earlier were consulted.

This questionnaire consist of 45 questions, take account of ten (8) variables. The survey, along with participant observation and interviews with key informants, was carried out during the year $1^{\text {st }}$ march ,2010 to $28^{\text {th }}$ June 2011.During the survey special attention was given to establish good rapport with the AIDS patients by explaining to them the purpose of the study and assured them to protect their personal identity without dissimilation of the data .This step was very important to obtain reliable information because some AIDS patients might tend to provide incorrect information if they felt that the interviewers were not helpful. Simple statistical techniques are used to the data analysis Statistical Packages for Social Science (SPSS 16.0) are used to find out the problems of people living with HIV/AIDS. The multivariate statistical technique of factor analysis is applied to study the multi dimensional inter related variables included in the research study. Computer based cartographic technique is used to show the disparity in the spatial pattern and variation of HIV /AIDS infected people in the fourteen district of Kerala State. Arc GIS 9.3 is used to analyze and prepare maps for future planning to the Govt organizations.

\section{RESUlTS AND DisCUSSIONS}

The present study analyzed the spatial distribution of people living with HIV/AIDS and their relationship between social, cultural, psychological and health condition. On the basis of the discussions there are 62variables selected in the statistical analysis. They are the information collected from the primary survey of the People Living with HIV/AIDS in the major 8 subdivisions consists of 62 variables such as the Personal status and Living environmental conditions, Awareness of HIV/AIDS and Source of infection, Knowledge about Sex, Practice and Behaviour, Usage of preventive tools, Social, Psychological and opportunistic disease related health problems. Availability, accessibility and affordability of health care facilities and Role of NGO and Government towards HIV/AIDS prevention.

The secondary base 10 variables of the health care facility includes service infrastructural indicators such as health care services such as number of health centres, health centre density index, number of doctors, number of beds, availability of beds in hospital as, number of welfare centre, family welfare centre, health centre density, health index literacy rate. The entire interrelated variable in the data matrix of $13 \times 72$ is used for statistical analysis.

Table1.1. Data set of Primary sample of People Living with HIV/AIDS and Secondary data

\begin{tabular}{|l|l|l|l|}
\hline 1 & Male & 11 & High school level of education \\
\hline 2 & Female & 12 & Higher secondary level of education \\
\hline 3 & 20-29 Age group & 13 & Unskilled worker \\
\hline 4 & $30-39$ Age group & 14 & Truck and Auto drivers \\
\hline 5 & Marital status - Single & 15 & Unemployed \\
\hline 6 & Marital status -Married & 16 & House wife \\
\hline
\end{tabular}


Social Perceptions of People Living with HIV/AIDS using Multivariate Analysis for Public Health Planning

\begin{tabular}{|c|c|c|c|}
\hline 7 & Hindu & 17 & Monthly income $<2000$ rupees \\
\hline 8 & Muslim & 18 & Marital life span 5--10 years \\
\hline 9 & Christian & 19 & Stay with family \\
\hline 10 & 4 to 6 members in the family & 20 & PLHA are out of station $7-14$ days \\
\hline II & \multicolumn{3}{|l|}{ Awareness of HIV/AIDS and Source of Infection } \\
\hline 21 & HIV/AIDS as Treacherous disease & 25 & HIV/AIDS Transmitted trough mother to child \\
\hline 22 & HIV/AIDS transmitted through Sexual contact & 26 & Confirmation of HIV/AIDS 3-6 years \\
\hline 23 & HIV/AIDS transmitted through drug abuse & 27 & personal disagreeable at the time of HIV/AIDS test \\
\hline 24 & HIV/AIDS transmitted through unsterilized syringe & 28 & Reveal test result to the partner \\
\hline III & \multicolumn{3}{|l|}{ Knowledge about Sex and Practice } \\
\hline 29 & Knowledge about sex from books & 33 & PLHA have Homosexuality \\
\hline 30 & Knowledge about sex from friends & 34 & PLHA have habit of visit sex workers \\
\hline 31 & PLHA have Sex before marriage & 35 & PLHA have Anal intercourse \\
\hline 32 & $\begin{array}{l}\text { PLHA Age of first sexual intercourse } 15-25 \text { age } \\
\text { group }\end{array}$ & 36 & PLHA out of station \\
\hline IV & \multicolumn{3}{|l|}{ Usage of Preventive Tools } \\
\hline 37 & Partner prevents Condom & 40 & Anal intercourse \\
\hline 38 & Insisted condoms by partner & 41 & Due to unpleasant staff unable to purchase condom \\
\hline 39 & yourself insisted condom & 42 & PLHA getting Condom freely \\
\hline VI & \multicolumn{3}{|c|}{ Social and Psychological Health Problems of HIV/AIDS Infected Persons } \\
\hline 43 & $\begin{array}{l}\text { PLHA bothered about family members getting } \\
\text { HIV/AIDS }\end{array}$ & 49 & PLHA suffer loss of weight \\
\hline 44 & Separated from the family & 50 & PLHA suffer Fever \\
\hline 45 & PLHA Isolated due to HIV/AIDS & 51 & PLHA suffer Headache \\
\hline 46 & PLHA Dejection due to HIV/AIDS & 52 & PLHA suffer Night sweat \\
\hline 47 & PLHA suffer disease daily & 53 & PLHA suffer Oral thrush \\
\hline 48 & PLHA suffer Fatigue & 54 & PLHA suffer Tuberculosis \\
\hline \multicolumn{4}{|c|}{ IX Availability, Accessibility and Affordability of Health Care Facilities to the Infected Persons } \\
\hline 55 & ART treatment free & 57 & PLHA ART treatment access is difficult \\
\hline 56 & PLHA Treatment receiving from Govt hospital & 58 & Getting nutritious food \\
\hline 59 & PLHA Satisfied the work of NGO & 61 & $\begin{array}{l}\text { PLHA not satisfied the GOVT agencies role to } \\
\text { control HIV/AIDS }\end{array}$ \\
\hline 60 & PLHA getting moral help from NGO & 62 & Medical practitioner visited PLHA home \\
\hline $\mathbf{X}$ & \multicolumn{3}{|c|}{ Demographic Characteristics (Secondary data base) } \\
\hline 63 & Number of Health centres & 68 & No. of Welfare Centre \\
\hline 64 & Health centre density index & 69 & Family Welfare Centre/000 population \\
\hline 65 & No of doctors per 1000 population & 70 & Health centre density/10sq.km \\
\hline 66 & No of Beds & 71 & Health Index \\
\hline 67 & Availability of Beds in Hospitals & 72 & Literacy rate \\
\hline
\end{tabular}

\subsection{HIV/AIDS Related Variables Relationship and Factor Solution:}

The extraction of table 1.2 illustrate the total variance explained by the variables included in the analysis.The distribution of Eigen values and the total percentage and cumulative percentage variance of each one of the factor solution is presented in table 1.2 , it is pertinent to note that 13 factors with 6.43 rotated Eigen vector values explains $100 \%$ of the variance in the data set. The factor loading of each one of all the 72 HIV/AIDS related variables are item wise listed in table1.2 .

The Eigen value 6.49 is considered as a yardstick to extract 10 factors and the same are resolved owing to the fact that almost all the variables got loaded with these factors. The 10 factors explain altogether $89.58 \%$ of the total variance with each one of its value ranging from $6.49 \%$ to $12.31 \%$. Though the components selected as 10 factors, it is pertinent to note the fact the first 5 primary factors that have more than 8.93 Eigen values alone totally explain $53.84 \%$ of total variance whereas the remaining 5 factors recorded with more than (6.49-7.61). Eigen values altogether explain only 35.74 $\%$ of the total variance. In fact, among the first 3 primary factors the first component alone with its Eigen value 34.52 explain highest amount of total variance that is about $10.82 \%$ followed by the rest of 7 factors that explain the total variance of around $6.49 \%$ viz the second component $(11.39 \%)$, 
Social Perceptions of People Living with HIV/AIDS using Multivariate Analysis for Public Health Planning

third $(10.82 \%)$ fourth $(10.39 \%)$ and fifth $8.93 \%$. These entire 5 variables explain $53.84 \%$ of the total variance of the data set.

Table1.2. Total variance explained

\begin{tabular}{|c|c|c|c|c|c|c|c|c|c|}
\hline $\begin{array}{l}\text { Com } \\
\text { pone } \\
\text { nt }\end{array}$ & $\begin{array}{l}\text { Initial } \\
\text { Eigen } \\
\text { values }\end{array}$ & & & \begin{tabular}{|lr} 
Extraction & Sums \\
of & Squared \\
Loadings & \\
\end{tabular} & & & 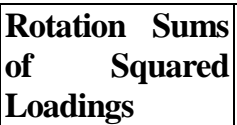 & & \\
\hline & Total & $\begin{array}{lr}\% & \text { of } \\
\text { Variance }\end{array}$ & $\begin{array}{l}\text { Cumula } \\
\text { tive } \%\end{array}$ & Total & $\begin{array}{lr}\% & \text { of } \\
\text { Variance }\end{array}$ & $\begin{array}{l}\text { Cumula } \\
\text { tive } \%\end{array}$ & Total & $\begin{array}{l}\% \text { of } \\
\text { Variance }\end{array}$ & $\begin{array}{l}\text { Cumul } \\
\text { ative \% }\end{array}$ \\
\hline 1 & 15.28 & 15.43 & 15.43 & 15.28 & 15.43 & 15.43 & 12.19 & 12.31 & 12.31 \\
\hline 2 & 14.29 & 14.44 & 29.87 & 14.29 & 14.44 & 29.87 & 11.27 & 11.39 & 23.70 \\
\hline 3 & 11.84 & 11.96 & 41.83 & 11.84 & 11.96 & 41.83 & 10.71 & 10.82 & 34.52 \\
\hline 4 & 10.28 & 10.38 & 52.21 & 10.28 & 10.38 & 52.21 & 10.29 & 10.39 & 44.91 \\
\hline 5 & 8.89 & 8.98 & 61.19 & 8.89 & 8.98 & 61.19 & 8.84 & 8.93 & 53.84 \\
\hline 6 & 7.45 & 7.52 & 68.71 & 7.45 & 7.52 & 68.71 & 7.53 & 7.61 & 61.45 \\
\hline 7 & 7.25 & 7.32 & 76.03 & 7.25 & 7.32 & 76.03 & 7.43 & 7.51 & 68.95 \\
\hline 8 & 6.22 & 6.28 & 82.31 & 6.22 & 6.28 & 82.31 & 7.36 & 7.44 & 76.39 \\
\hline 9 & 5.50 & 5.55 & 87.87 & 5.50 & 5.55 & 87.87 & 6.63 & 6.70 & 83.09 \\
\hline 10 & 4.76 & 4.80 & 92.67 & 4.76 & 4.80 & 92.67 & 6.43 & 6.49 & 89.58 \\
\hline 11 & 4.06 & 4.11 & 96.78 & 4.06 & 4.11 & 96.78 & 5.42 & 5.47 & 95.05 \\
\hline 12 & 3.19 & 3.22 & 100.00 & 3.19 & 3.22 & 100.00 & 4.90 & 4.95 & 100.00 \\
\hline
\end{tabular}

The remaining 5 factors, all of them have more than 4 Eigen values and they altogether explain little less than $35.74 \%$ of total variance. However it is to be further noted that these factors are strongly loaded with the following group of highly related variables that are considered in the analysis.

\subsection{Major Factors and their Variable Loadings}

The first component which explains $12.31 \%$ of the total variance is significantly loaded with 22 variables (see table 1.2). The factor loading positive values of 11 variables lies between (0.93 to 0.45$)$ in both the directions. MLHA Partner prevent condom usage with sexual intercourse (0.93), MLHA got Moral support from NGO (0.76), HIV /AIDS transferred to Mother to Child (0.62), FLHA separated from family (0.59), MLHA Married (0.59), High school level of education (0.59) MLHA suffered fever (0.56) MLHA reveal test to partner (0.56) FLHA got HIV/AIDS through Sexual contact (0.48) MLHA suffered TB (0.45) FLHA age group of 30-39 (0.45)

The 11 variables with negative loadings are added with Partner prevents condom usage $(-0.94)$ MLHA protect HIV themselves-0.93, MLHA receiving nutritious food-0.82, MLHA got HIV through Drug Abuse-0.68, FLHA isolated-0.61, FLHA have anal intercourse-0.55, MLHA have the age group of 30-39(-0.49), FLHA got HIV from Mother to Child transmission-0.48, No of Beds in the hospitals-0.45 MLHA collect the sex knowledge from Friends-0.45 MLHA living as single-0.44

Hence this $\mathbf{I}^{\text {st }}$ component is named as Dimension of Variation of the PLHA and their awareness and Sexual practice, Preventive tools and Psychological Problems.

The second component which accounts for $11.39 \%$ of the total variance includes 20 variables with strong loading values between 0.94 and 0.44 in both the directions. Among the 25 variables 16 show positive values of loading such as Health centre density index 0.94 , Health centre density/10sq.km0.94 No of doctors per 1000 population 0.88 Health Index 0.80 Number of Health centers0.73 FLHA receiving nutritious food( 0.64) 5 to10 (0.60), MLHA suffered headache0.56, Yourself0.53, Mother to Child transmission of HIV/AIDS0.50 ,Literacy rate0.50, MLHA not satisfied the work of Govt0.48, MLHA have sexual intercourse in the period of 15-25(0.46) FLHA have anal intercourse0.46, MLHA satisfied the work of NGO0.42, FLHA taking ART0.41,

The negatively loaded factors are FLHA as Christian-0.71, Male sex before marriage-0.54, FLHA Partner prevents condom usage-0.53, MLHA High school level education-0.48, MLHA have sex in the age group of 15-25(-0.46) MLHA are Unemployed (-0.45) MLHA are Christian community0.44.In total (5) variables are included under this dimension explained the characteristic of the general Heath care facility and accessibility and sexual knowledge and practice. Hence this component is named as Dimension of Health care facility and Availability of HIV/AIDS treatment

The III ${ }^{\text {rd }}$ component accounts $10.82 \%$ of total variance with positive loading values of 8 variables $(0.85-0.43)$ and 13 variables with negative loadings (-0.69 to-0.44). The variable such as MLHA 
belongs to Muslim community0.85 ,Access is difficult0.83, MLHA receiving treatment from Govt hospitals0.76, MLHA taking ART0.71, MLHA got HIV /AIDS through Sexual contact0.6, Friends0.63, FLHA have anal intercourse0.56, Involm0.46, MLHA know that HIV is a Infectious disease 0.44, Involve0.44, FLHA receiving nutritious food0.44, FLHA have first sexual relationship at the age group of (15-25) 0.44, MLHA Partner prevents condom usage 0.43, are loaded with positive direction.

While negatively loaded variable is MLHA belongs to Hindu community-0.69, MLHA visited sex workers home-0.64, FLHA separated from the family-0.63, MLHA separated from family-0.59, HIV/AIDS is a Infectious disease-0.53, MLHA believes the support of NGO-0.53, 1--3 year-0.52, FLHA suffered headache-0.49, MLHA have Higher secondary level of education-0.47, MLHA have Dejection due to HIV-0.45, MLHA infected HIV through Drug Abuse-0.44.

All these 24 factors in variably cluster and explained Availability and accessibility of ART treatment and role of NGO and Govt. Therefore this component is rightly called as Dimension of Availability and accessibility of ART treatment and role of NGO and Govt .

In the IV th component exhibit the total variance of $10.39 \%$ is contributed by 19 variables. The positive loading 9 variable factors lying between 0.91 and 0.41 in both the directions. Among them, Availability of Beds in Hospitals0.91, MLHA frustrated due to HIV/AIDS infection0.73, Involvement 0.71, MLHA have anal inter course0.68, FLHA infected HIV/AIDS through Sexual contact0.64, FLHA have High school level of education0.53, No of Beds0.48, FLHA taking ART0.41 MLHA have 4-6 members in the family0.41.

Of the remaining 10 negative variables are namely people living with HIV/AIDS have Availability of Beds in Hospitals0.91 MLHA frustrated due to HIV/AIDS infection0.73 Involm0.71, MLHA have anal inter course0.68,FLHA infected HIV/AIDS through Sexual conta0.64 ,FLHA have High school level of education0.53, No of Beds0.48, FLHA taking ART0.41, MLHA have 4--6 family members0.41.This component is conveniently stated as Psychological problems of the HIV/AIDS infected people's personal status and awareness about HIV/AIDS.

The $\mathbf{V}^{\text {th }}$ component explains $(8.93 \%)$ the total variance with 13 variable factors. Of the total number of the 7 positive variable expressed as PLHA presently using MLHA collect sexual knowledge from Books0.91 MLHA out of station <7,0.84 FLHA suffering fever0.73, FLHA 20-30 age group0.67, MLHA have sex before marriage 0.64 MLHA are engaged as Unskilled truck auto drivers0.63 MLHA engaged first sex work 15--25 age group0.43.

The negatively loaded 3 variables are MLHA suffered HIV/AIDS in 1--3 year-0.90 MLHA not interest in life-0.73 ,MLHA bothered about family-0.62, FLHA 30-39 age group-0.56 , MLHA reveal test to partner-0.43, MLHA believes HIV/AIDS is Infectious disease-0.41.As this component explain the multidimensional determinant factors of People Living with HIV/AIDS and the sexual knowledge here this dimension is named as Dimension of Variation of sexual knowledge and practice among the PLHA.

The VI ${ }^{\text {th }}$ component account for only $7.61 \%$ of the total variance and loaded with 11 variables in the dimension of sexually transmitted disease and rural population. The dimension of FLHA believes Access is difficult to treatment0.81, Family Welfare Centre/000 population0.77, FLHA suffered HIV/AIDS0.68, FLHA got Moral support0.68 ,No. of Welfare Centre0.62, FLHA Sexual contact 0.50 , MLHA have 4--6 family members 0.45 are positively loaded. While the negative variable considered as FLHA lived 2--4 years-0.80, FLHA <2000 rupees-0.67, MLHA Partner prevents condom use-0.60, FLHA transferred HIV trough Mother to Child-0.50.All the positive loading variables cluster around accessibility of treatment than the negatively loaded variables. Hence this component explains the Dimension of treatment difficulty and the role of Govt welfare centres and NGO in the prevention activities.

The VII ${ }^{\text {th }}$ component explains $(7.51 \%)$ of total variance together with 11 variables ranging from (0.43 to0.91) The variable such as FLHA got sex knowledge from friends0.91, MLHA bothered about family0.56, MLHA in the age group (30-39)0.54, No of Beds0.52, FLHA believes the HIV/AIDS are Infectious0.52, FLHA in the age group 30-39 (0.49). Whereas the negative factors FLHA got sex knowledge from Books -0.91, MLHA in the age group of (20-30)-0.77,Use of unsterilized syring-0.46, Family Welfare Centre/000 population-0.45, FLHA in the age group of 2030-0.43.These factors simply associated with the living condition of PLHA, botheration about family 
and the comprehensive knowledge about HIV/AIDS so that it is aptly called as the Dimension of sexual knowledge and personal status of PLHA.

The VIII ${ }^{\text {th }}$ components explains $(7.44 \%)$ of the total variance with loading of 0.44 to 0.90 in both direction. This positively loaded variables are the FLHA belongs to Muslim community0.90, FLHA isolated from the society0.58, MLHA believes HIV is a Infectious0.45 ,MLHA suffered TB0.45, FLHA Moral0.45, MLHA Sexual contact0.42, MLHA got sex knowledge from Friends0.42.The negatively loaded factors are business FLHA Hindu community-0.92, FLHA bothered family-0.74, MLHA have first sex in the age group of 15--25-0.62, MLHA High school level education-0.51, FLHA Frustrated due to HIV/AIDS-0.44.These 11 factors strongly associated with the HIV/AIDS infected population, their level of literacy, awareness, disease so that it is aptly named as the FLHA isolation from the society and the role of NGO.

The IX ${ }^{\text {th }}$ component explains $(6.70 \%)$ of the variations in the data matrix with a 11factor loading in both direction (0.41 to 0.80). The positive variables such as FLHA Frustrated due to the HIV infection 0.80, MLHA isolated from society 0.71 ,MLHA under ART 0.67, MLHA are Unemployed0.58, MLHA engaged as Unskilled truck auto drivers0.54, MLHA Higher secondary level of education0.50,MLHA Married0.49 ,FLHA suffered TB 0.42, No. of Welfare Centre0.41.The remaining 3 negatively loaded factors are FLHA Not interest in life-0.78, FLHA 1--3 year-0.55, FLHA reveal the test result to the partner - 0.41 . On the basis of cluster and association it is treated as the Dimension of MLHA isolated from the society and treatment seeking behaviour.

The $\mathbf{X}^{\text {th }}$ component explains $(6.49 \%)$ of the variations in the data matrix with an 11 factor loading in both direction (0.41 to 0.89). The positive variables such as FLHA Married0.89, FLHA reveal test result to partner0.65 MLHA Christian community, 0.56 FLHA getting nutritious food0.44; FLHA believed HIV/AIDS is an Infectious disease 0.42. The remaining 6 negatively loaded factors are FLHA lived as Single-0.89, FLHA out of station $<7$ days-0.57, MLHA suffered fever -0.49, MLHA belongs to Hindu community -0.48 , MLHA have 4-6 family members - 0.48 , MLHA getting nutritious food0.41 . On the basis of the cluster and association it is treated as the Dimension of the religious background, marital status and diagnosis of HIV/AIDS test result to the partner.

The input data of 72 variables both primary and secondary information of People Living with HIV/AIDS in Palakkad district is summarised into ten factors. The factor loading explains with ten dimensions of the People living with HIV /AIDS in Palakkad and their associated problems. But in the spatial context it shows variation in the magnitude of the problem. Hence the best related well explained shows the 10 dimensions.

\subsection{PLHA an Integrated Approach for the Public Health Planning}

The component scores derived for each observation areal unit of the Palakkad districts in the Kerala State shows the spatial variation in the respective factor score. The positive and negative scores pertaining to each component shows the problems related to People Living with HIV/AIDS in the blocks of Palakkad district. In the present analysis all the components are selected based on the dimension related to People Living with HIV/AIDS in Palakkad district.

Table1.3. Palakkad: Block wise distribution of the Composite Index values

\begin{tabular}{|l|r|r|r|r|r|r|r|r|r|r|r|}
\hline Blocks & $\begin{array}{l}\text { Factor } \\
\text { I }\end{array}$ & $\begin{array}{l}\text { Factor } \\
\text { II }\end{array}$ & $\begin{array}{l}\text { Factor } \\
\text { III }\end{array}$ & $\begin{array}{l}\text { Factor } \\
\text { IV }\end{array}$ & $\begin{array}{l}\text { Factor } \\
\text { V }\end{array}$ & $\begin{array}{l}\text { Factor } \\
\text { VI }\end{array}$ & $\begin{array}{l}\text { Factor } \\
\text { VII }\end{array}$ & $\begin{array}{l}\text { Factor } \\
\text { VIII }\end{array}$ & $\begin{array}{l}\text { FactorI } \\
\text { X }\end{array}$ & $\begin{array}{l}\text { Factor } \\
\text { X }\end{array}$ & $\begin{array}{l}\text { Composite } \\
\text { index }\end{array}$ \\
\hline Alathur & -1.96 & 0.19 & 2.26 & 0.29 & 0.51 & -0.50 & -0.18 & 0.60 & 0.20 & -0.33 & 1.08 \\
\hline Attapadi & 0.60 & -1.38 & 0.05 & 2.11 & 0.06 & 1.51 & -0.53 & -0.21 & 0.07 & 0.41 & 2.69 \\
\hline Chittur & 0.05 & 0.32 & -0.40 & 1.58 & -0.35 & -2.01 & 0.85 & -0.59 & -1.64 & -0.28 & -2.48 \\
\hline Kollamgode & 0.07 & 1.27 & -0.17 & -0.36 & 1.45 & 0.26 & -2.25 & -0.56 & -0.82 & 0.41 & -0.71 \\
\hline Kuzhalmannam & 0.22 & -0.70 & -0.04 & 0.20 & 0.06 & 0.36 & -0.21 & -0.89 & 0.10 & -0.28 & -1.19 \\
\hline Malampuzha & 0.87 & -1.24 & 1.31 & -1.22 & 0.51 & 0.59 & 1.08 & 0.33 & -0.92 & -0.49 & 0.83 \\
\hline Mannarkkad & -1.72 & 0.03 & -1.16 & -0.48 & -0.29 & 0.93 & 1.03 & 0.40 & -0.63 & 1.98 & 0.08 \\
\hline Nenmara & -0.08 & -1.66 & -1.18 & -0.55 & 0.09 & -1.54 & -1.10 & 1.55 & 0.78 & -0.08 & -3.09 \\
\hline Ottapalam & 0.64 & 0.04 & -0.33 & -1.57 & -0.50 & -0.06 & -0.01 & -0.78 & -1.04 & -0.38 & -3.99 \\
\hline Palakkad & 0.69 & 0.37 & 1.06 & -0.36 & -1.85 & -0.63 & -0.36 & -0.92 & 1.36 & 1.44 & 0.81 \\
\hline Pattambi & 0.86 & 0.84 & -0.41 & 0.10 & 2.00 & -0.39 & 1.50 & -0.16 & 1.63 & 0.36 & 6.33 \\
\hline Sreekrishnapuram & 0.96 & 1.63 & -0.07 & 0.41 & -1.02 & 0.77 & 0.03 & 2.24 & -0.16 & -0.64 & 4.15 \\
\hline Thrithala & -1.20 & 0.28 & -0.92 & -0.15 & -0.66 & 0.71 & 0.16 & -1.01 & 1.06 & -2.11 & -3.85 \\
\hline
\end{tabular}

Source: Compiled by researcher 
3.3.1. Factor I Dimension of Variation of the PLHA and their awareness and Sexual practice, Preventive tools and Psychological Problems

Table1.3and shows High factor score represented in Sreekrishnapuram 0.96 , Malampuzha 0.87 Pattambi 0.86, Palakkad 0.69, Ottapalam 0.64, Attapadi 0.60, Kuzhalmannam 0.22, Kollamgode 0.07 , Chittur 0.05 next with medium positive factor score(Zero to+1) in this dimension. Low negative score identified from Nenmara blocks-0.08 ranks third order with low negative score (less than 1). The blocks of Thrithala -1.20, Mannarkkad -1.72, Alathur -1.96 register high negative factor score.

\subsubsection{Factor II Dimension of Health care facility and Availability of HIV/AIDS treatment}

The table 1.3 and demonstrates the Dimension of Health care facility and Availability of HIV/AIDS treatment highlight Sreekrishnapuram1.63 Kollamgode1.27 in Palakkad district have very high positive score value .Table 1.3 and figure 1.2 . In seven blocks has low positive score (0 to +1 ) i.e. Pattambi0.84 Palakkad0.37 Chittur0.32, Thrithala0.28, Alathur0.19, Ottapalam0.04 and Mannarkkad0.03.Low negative score observed (0- -1$)$ only in Kuzhalmannam block -0.70 .While high negative (>-1) factor score represented in Malampuzha -1.24, Attapadi-1.38 and Nenmara-1.66.

\subsubsection{Factor III Dimension of Availability and accessibility of ART treatment and role of NGO and Govt.}

Dimension of Availability and accessibility of ART treatment and role of NGO and Govt draw attention to Alathur 2.26, Malampuzha 1.31 and Palakkad1.06 blocks in Palakkad district have very high positive score value. Table 1.3 and figure 1.2. low positive $(0$ to +1$)$ score represented only in Attapadi block 0.05. Low negative score observed only in seven blocks (0- -1$)$ Kuzhalmannam-0.04, Sreekrishnapuram-0.07, Kollamgode-0.17 Ottapalam-0.33 ,Chittur-0.40 ,Pattambi-0.41 ,Thrithala0.92 . While high negative (>-1) score represented in two blocks Mannarkkad-1.16 and Nenmara1.18 .

\subsubsection{Factor IV Dimension of Psychological problems of the PLHA, personal status and} awareness about HIV/AIDS

Dimension of Psychological problems of the PLHA, personal status and awareness about HIV/AIDS bring to light Attapadi 2.11 and Chittur1.58 blocks in Palakkad have very high positive score value .Table 1.3 and figure 1.2. In four blocks has low positive $(0$ to +1$)$ i.e. Sreekrishnapuram 0.41 , Alathur0.29, Kuzhalmannam0.20 and Pattambi0.10. Low negative score observed in (0- -1$)$ represented in Thrithala-0.15, Palakkad-0.36, Kollamgode-0.36, Mannarkkad-0.48 and Nenmara0.55.While high negative (>-1) score represented in Malampuzha-1.22 and Ottapalam-1.57.

\subsubsection{Factor V Dimension of Variation of sexual knowledge and practice among the PLHA.}

Dimension of Variation of sexual knowledge and practice among the PLHA highlight Pattambi2.00 and Kollamgode1.45 blocks in Palakkad district having very high positive score value. Table 1.3 and figure 1.2 In five blocks has low positive $(0$ to +1$)$ i.e. Malampuzha 0.51, Alathur0.51, Nenmara0.09, Attapadi 0.06 and Kuzhalmannam 0.06 . Low negative score observed in $(0--1)$ in the blocks of Mannarkkad-0.29 and Chittur-0.35 Ottapalam-0.50 and Thrithala-0.66. While high negative (>-1) represented in Sreekrishnapuram-1.02 and Palakkad-1.85.

\subsubsection{Factor VI Dimension of treatment difficulty and the role of Govt welfare centers and NGO in the prevention activities.}

Dimension of treatment difficulty and the role of Govt welfare centres and NGO in the prevention activities highlight Attapadi blocks 1.51 in Palakkad having very high positive score value .Table 1.3 In six blocks has low positive $(0$ to +1$)$ i.e. Mannarkkad0.93 ,Sreekrishnapuram0.77, Thrithala0.71, Malampuzha0.59, Kuzhalmannam0.36,Kollamgode0.26. Low negative score observed in (0- -1) Ottapalam-0.06, Pattambi-0.39, Alathur-0.50 and Palakkad-0.63. While high negative score represented (>-1) in Nenmara-1.54 and Chittur-2.01 .

\subsubsection{Dimension of sexual knowledge and personal status of PLHA.}

The table 1.3 lay emphasis on the Dimension of sexual knowledge and personal status of PLHA. Pattambi1.50, Malampuzha1.08 and Mannarkkad1.03 in Palakkad having very high positive score 
value. In three district has low positive $(0$ to +1$)$ i.e. Chittur0.85, Thrithala0.16 and Sreekrishnapuram 0.03. Low negative score observed in five blocks i.e. (0- -1) Ottapalam-0.01, Alathur-0.18, Kuzhalmannam-0.21 ,Palakkad-0.36, Attapadi-0.53. While high negative (>-1) score represented in Nenmara-1.10 and Kollamgode-2.25.

\subsubsection{Dimension FLHA isolation from the society and the role of NGO.}

It is seen from the table 1.3 Dimension of FLHA isolation from the society and the role of NGO lay emphasis on Sreekrishnapuram2.24 and Nenmara1.55 in Palakkad district having very high positive score value .Table 1.3 and figure 1.2. In three district has low positive $(0$ to +1$)$ i.e. Alathur 0.60 , Mannarkkad0.40 and Malampuzha0.33. Low negative score observed in seven blocks (0- -1$)$ Pattambi-0.16, Attapadi-0.21, Kollamgode-0.56, Chittur-0.59, Ottapalam-0.78, Kuzhalmannam-0.89 and Palakkad-0.92. While high negative score (>-1) represented in Thrithala-1.01.

\subsubsection{Dimension of MLHA isolated from the society and treatment seeking behaviour}

It is make obvious from the table 1.3 the Dimension of MLHA isolated from the society and treatment seeking behaviour very high positive score value in the blocks of Pattambi1.63, Palakkad1.36 and Thrithala1.06 in Palakkad district. In four district has low positive $(0$ to +1$)$ i.e. Nenmara0.78, Alathur0.20 Kuzhalmannam0.10 and Attapadi0.07. Low negative score observed in (0- -1$)$ Sreekrishnapuram-0.16, Mannarkkad-0.63, Kollamgode-0.82 and Malampuzha-0.92.While high negative (>-1) score represented in Ottapalam-1.04 and Chittur-1.64.

\subsubsection{Factor $X$ Dimension of the religious background, marital status and diagnosis of HIV/AIDS test result to the partner.}

Table 1.3 shed light on the Dimension of the religious background, marital status and diagnosis of HIV/AIDS test result to the partner .Mannarkkad1.98 and Palakkad1.44. having very high positive score value. In three blocks has low positive $(0$ to +1$)$ i.e. Kollamgode0.41, Attapadi0.41 and Pattambi0.36 .Low negative score observed in (0- -1$)$. Nenmara-0.08, Chittur-0.28, Kuzhalmannam0.28, Alathur-0.33, Ottapalam-0.38 Malampuzha-0.49 and Sreekrishnapuram-0.64. While high negative score (>-1) represented in Thrithala-2.11.

\subsection{A GIS Approach to Public Health Planning for the People Living with HIV/AIDS}

The spatial variation people living with HIV/AIDS and health care facility is in complex nature to the pattern of multidimensional character and identify the specific strategy for planning health services. Hence a composite multi score is computed and GIS Maps is being used to explore the problem area identification. Blocks with Very High HIV/AIDS related problems composite index value (+>2) registered in Pattambi 6.33, Sreekrishnapuram 4.15 and Attapadi block 2.69 score value. High HIV /AIDS related problems 4 blocks in Palakkad district be a sign of medium index +2 to 0 of HIV/AIDS related problems ie Alathur1.08, Malampuzha0.83, Palakkad0.81 and Mannarkkad 0.08.

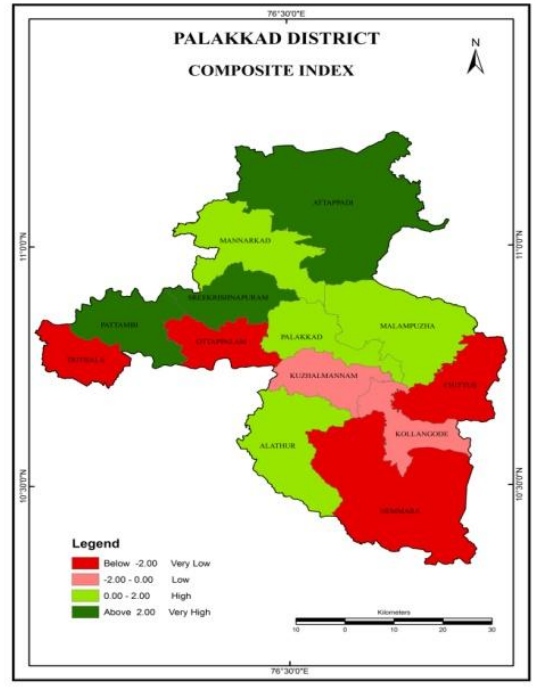

Figure 1.2 
Blocks with low HIV/AIDS related problems Only 2 blocks in Palakkad districts stand for low index value $\mathbf{0}$ to $-\mathbf{2}$ i.e. Kollamgode- 0.71 and Kuzhalmannam-1.19. Blocks with very low HIV/AIDS related problems only 4 blocks in Palakkad district with very low index value $\mathbf{- 2}$ to $-\mathbf{4}$. It is represented in the blocks of Chittur-2.48, Nenmara-3.09, Thrithala-3.85 and Ottapalam-3.99.

\section{Conclusion}

The availability of micro level health data related to the people living with HIV/AIDS, the expansion of software solutions, advancement in computer capabilities, and a growing interest in health disparities have promoted the rising profile of health mapping. Spatial distribution people living with HIV/AIDS and their relationship between social, cultural, psychological and health condition are considered for the present analysis and identified the problematic region in the block level i.e. Pattambi, Sreekrishnapuram and Attapadi block moderate of HIV/AIDS related problems identified from Alathur,Malampuzha, Palakkad and Mannarkkad. blocks with low HIV/AIDS related problems i.e. Kollamgode and Kuzhalmannam. blocks with very low HIV/AIDS related problems are represented in the blocks of Chittur, Nenmara-, Thrithala, and Ottapalam- this will be ready to lend a hand for a sustainable planning to the future.

\section{REFERENCE}

[1] Ajithkumar, S Irudayarajan (2006) Medical Care for HIV An Opportunity or Crisis? Economic and Political Weekly, pages 1429-1430

[2] Akhtar, Rias, (2007) "Changing Disease Ecology of Leh District: Contemporary Scenario and Historical Perspective" Punjab Geographer 3, 39-44

[3] Akhtar, R., A. Learmonth, and Milton Keynes. (1977) "The resurgence of malaria in India 1965-76." GeoJournal 1.5, 69-80.

[4] Alan Bryman and Duncan Cramer, (2001) Quantitative Data Analysis with SPSS 10 for windows A Guide for Social Scientists, Taylor \& Francis Inc USA.

[5] Alan N Zuckerman (2005) Health care strategic planning, $2^{\text {nd }}$ edition, Health Administration Press Chicago, Illinois.

[6] Anderson, T.W.(1958), Introduction to Multivariate Statistical Analysis. John Wiley and Sons, Inc. New York

[7] Jayarajan K. and K. Lakshmi (2014 )Living environmental conditions of the HIV/AIDS infected persons in Kerala, India ,Archives of Applied Science Research, 6 (1):52-59 (http://scholarsresearchlibrary .com/archive.html)

[8] Jayarajan K, K Lakshmi (2014) Geographic Variation of Sexual Knowledge and Practice among the People Living with HIV/AIDS in Kerala State, India The International Journal Of Humanities \& Social Studies Vol 2 Issue 1 January, 2014 (ISSN 2321 - 9203)

[9] Jayati Das, (2007), "Health Mapping of Water Borne Diseases", Indian Journal of Landscape Systems and Ecological Studies 30(2), 59-62.

[10] J Elamon A situational analysis of HIV/AIDS-related discrimination in Kerala, India. (2005) AIDS Care Volume: 17 Suppl 2, Issue: Supplement 2, Pages: S141-S151

[11] Jha, Madhbendra Kumar, (2009), "Health status of tribal women in India", Indian Journal of Regional Science, 41(2), 30-37.

[12] Kachur, R. E., (2004), The Internet Alert Project: spreading the word about high-risk sexual activities advertised on the Internet. AIDS Care, Vol. 16 Issue 8, p971-976.

[13] Kalichman, Seth C.; Klein, Susan J.; Kalichman, Moira O.; O'Connell, Daniel A.; Freedman, Jay A.; Eaton, Lisa; Cain, Demetria (2007), HIV/AIDS Case Managers and Client HIV Status Disclosure: Perceived Client Needs, Practices, and Services. Health \& Social Work, Nov2007, Vol. 32 Issue 4, p259267

[14] Kalwar, S.C. and Yadav, Lala Ram, (2008),"Fluoride and Human Health - A Case Study of Chaksu Tehsil of Jaipur District, Rajasthan", Annals of the Rajasthan Geographical Association, XXV, 65-73.

[15] Rupa Chinai (2009), HIV/AIDS in India: The Wider Picture Economic \& Political Weekly, page 79-83 vol 33.

[16] Santra Prakasnaryan, (2010), "Status of Maternal and Child Health in West Bengal", Geographical Review of India, 72 (4), 414- 419.

[17] Santosh Vijaykumar, (2007), HIV/AIDS Treatment Education Is Critical Economic and Political Weekly April 7, vol 74 page 1249-251 
[18] K G Santhya, Shireen J Jejeebhoy, (2007) HIV/AIDS Risk Factors among Young Women in India ,Economic and Political Weekly April 7, page 1291-1297 vol -14

[19] Saranabhavan, V,(1993), "Materials on the Medical Geography of Mountain Landscapes", Soviet Geography, Vol.3, pp.20-41.

[20] Saravanabhavan, V etal 2006 Travel and Health care utilization pattern of patients vadipatti Panchayat union- A micro level study using GIS, The deccan Geographer LXIV(2)97-108

[21] Wang Shuguang; de Ven, Paul Van, (2003), peer HIV/AIDS education with volunteer trishaw drivers in yaan, people's republic of china: process evaluation. AIDS Education \& Prevention, Aug2003, Vol. 15 Issue 4,

[22] Winiarski, M. G.; Beckett, E.; Salcedo, J., (2005), Outcomes of an inner-city HIV mental health programme integrated with primary care and emphasizing cultural responsiveness. AIDS Care, Aug2005, Vol. 17 Issue 6, p747-756

Citation: Jayarajan.K. "Social Perceptions of People Living with HIV/AIDS using Multivariate Analysis for Public Health Planning”. International Journal of Research in Geography. vol 4, no. 1, 2018, pp. 67-77. doi:http://dx.doi.org/10.20431/2454-8685.0401009.

Copyright: (C) 2018 Authors. This is an open-access article distributed under the terms of the Creative Commons Attribution License, which permits unrestricted use, distribution, and reproduction in any medium, provided the original author and source are credited. 